\title{
Ab-Initio Reinvestigation of the (Sr-In) Binary System
}

\author{
Raouf Beddiaf ${ }^{*}$, Yassin Djaballah ${ }^{1}$, Hichem Bouderba ${ }^{2}$ \\ ${ }^{1}$ Laboratory of Physical and Chemical Study of Materials (LEPCM), Physics Department, Faculty of Science, \\ University of Batna, Algeria, 05000, Algeria. \\ ${ }^{2}$ Science and Technology Department, Faculty of Technology, University of Gherdaia, 47000, Algeria. \\ * Corresponding author. Tel.: +213661119837; email: rbeddiaf@gmail.com \\ Manuscript submitted March 5, 2015; accepted June 5, 2015. \\ doi: 10.17706/ijapm.2015.5.3.227-233
}

\begin{abstract}
Sr-In intermetallics were studied by first-principles calculations within density functional theory (DFT) with the projector augmented-wave technique (PAW) and the generalized gradient approximations (GGA) as implemented in the ABINIT code. Six intermetallics: SrIn5, SrIn3, SrIn2, SrIn, Sr5In3 and Sr3In were investigated in their observed experimental structures. The lattice constants, enthalpies of formation and bulk modulus of the Sr-In intermetallics have been calculated. The calculated lattice constants and enthalpies of formation are in good agreement with experimental and other theoretical results.
\end{abstract}

Key words: Sr-In compounds, crystal structure, first principles, ABINIT.

\section{Introduction}

The experimental informations concerning the Sr-In system have been summarized by Wang et al. [1]. The experimental phase diagram was drawn by Bruzzone [2] using thermal analysis (TA), metallographic methods and X-ray diffraction (XRD). Eight intermetallic phases $\operatorname{SrIn}_{5}, \operatorname{SrIn}_{3}, \operatorname{Sr}_{2} \operatorname{In}_{5}, \operatorname{SrIn}_{2}, \operatorname{Sr}_{2} \operatorname{In}_{3}, \operatorname{SrIn}_{,} \operatorname{Sr}_{3} \operatorname{In}_{2}$, and $\mathrm{Sr}_{3} I n$ were reported (Fig. 1). The $\mathrm{SrIn}_{2}$ and $\mathrm{Sr}_{3} \mathrm{In}$ phases melt congruently at $930{ }^{\circ} \mathrm{CK}$ and $558{ }^{\circ}$ Crespectively. The other compounds $\operatorname{SrIn}_{5}, \operatorname{SrIn}_{3}, \mathrm{Sr}_{2} \mathrm{In}_{5}, \mathrm{Sr}_{2} \mathrm{In}_{3}$, SrIn and $\mathrm{Sr}_{3} \operatorname{In}_{2}$ were formed via the peritectic reactions. Later Bruzzone et al. [3] reported a $\mathrm{Sr}_{5} \mathrm{In}_{3}$ phase instead of $\mathrm{Sr}_{3} \mathrm{In}_{2}$ and determined the crystal structure of $\mathrm{Sr}_{5} \mathrm{In}_{3}$ to be $\mathrm{Cr}_{5} \mathrm{~B}_{3}$ type crystal by single crystal and powder techniques and in the work of Wang et al. [1] the $\mathrm{Sr}_{5} \operatorname{In}_{3}$ phase was considered instead of $\mathrm{Sr}_{3} \operatorname{In}_{2}$, which was consistent with the assessment of Okamoto [4].

The crystallographic structures of the pure elements $\mathrm{Sr}$ and In were determined by Hirst et al. [5] and Moshopoulou et al. [6]. Bruzzone [2] determined also the structure of the $\operatorname{SrIn}_{5}, \operatorname{SrIn}_{3}$ and $\mathrm{Sr}_{3} I n$, the first compound crystallize as hp6 type (P6/mmm, Cacu $)$, the second hp8 (P63/mmc, $\left.\mathrm{Mg}_{3} \mathrm{Cd}\right)$, while the $\mathrm{Sr}_{3} \mathrm{In}$ is cubic cF16 (Fm3m, BiF $)$. The $\mathrm{SrIn}_{2}$ compound was studied by Iandelli [7] (hp6 type, $\mathrm{P} 6_{3} / \mathrm{mmm} \mathrm{CaIn}$ ) and the structure of the intermetallic SrIn was determined by Wendorff et al. [8] as oF64 type (Fdd2, SrIn). The structure the compounds $\mathrm{Sr}_{2} \mathrm{In}_{5}$ andSr 3 In were not determined until today.

The aim of the present work, based on first-principles calculations, is to investigate the relative stabilities of the different compounds involved in the Sr-In system. Having our calculations performed at $0 \mathrm{~K}$, we will be mainly focusing on the determination of the ground state line of this system.

\section{First-Principles Methodology}

Our calculations were performed using the ABINIT code [9], [10] which is based on the plane wave 
pseudo potential approach in the framework of the density functional theory (DFT) [11]. We used the projector augmented wave (PAW) method [12], [13] and the generalized gradient approximations (GGA) to treat the exchange interactions and correlation effects. The GGA is implemented according to the Perdew-Burke-Ernzerhof (PBE) functional [14]. The PAW atomic data sets for Strontium and Indium were generated with the Atom Paw code [15]. The atomic orbital's treated as valence states were 5s24p63d10 and 5s24d105p1 for Sr and In, respectively. The electron states were expanded in plane waves with kinetic energy cut-offs of $560 \mathrm{eV}$, and the Brillouin zone sampling was performed in such a way that the number of k-points multiplied by the number of atoms in the unit cell was greater than 104. A cold smearing [16] of $0.1 \mathrm{eV}$ was used. The above parameters enabled us to obtain a total energy convergence of $1 \mathrm{meV}$ per atom $(0.1 \mathrm{~kJ} / \mathrm{mol}$-atom $)$.

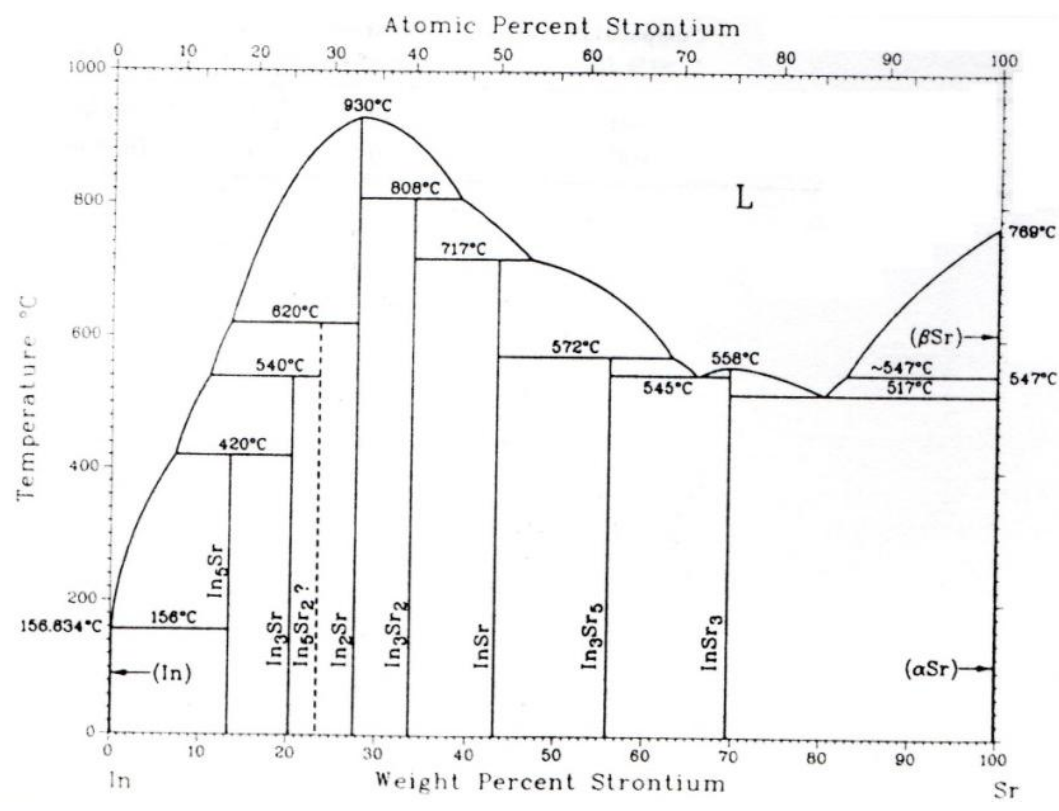

Fig. 1. Experimental phase diagram [2].

We carried out structure optimizations with respect to atom positions, cell shape and dimensions. After each full relaxation, self-consistent calculations were performed.

From the computed total energies of the equilibrium structures of all the phases considered we derived the corresponding enthalpies of formation at $0 \mathrm{~K}$, for the Sr-In system with general formula by applying the following equation:

$$
\Delta H_{f}\left(S r_{x} \operatorname{In}_{y}\right)=E_{t o t}\left(S r_{x} \operatorname{In}_{y}\right)-\left[\frac{x}{x+y} E_{t o t}^{b c c}(S r)+\frac{y}{x+y} E_{t o t}^{d i a}(\operatorname{In})\right] .
$$

where $E_{t o t}\left(S r_{x} I n_{y}\right), E_{t o t}^{b c c}(S r)$ and $E_{t o t}^{\text {dia }}(\operatorname{In})$ are the computed total energies (per atom) of the compound $S r_{x} I n_{y}$ and constituents, Sr and In, respectively, each one was relaxed to its equilibrium (zero pressure and forces) geometry.

\section{Results}

\subsection{Pure Elements}

We started the present investigation by computing the equilibrium lattice constants of pure elements $\mathrm{Sr}$ 
and In. In order to check the reliability of our generated atomic data sets, we compared them with experimental data and theoretical results. The results are shown in Table 1. The calculated lattice parameters show a good agreement with experiments and previous calculations from literature[1], [5], [6], [17], [18]. Thus, we can rely on our atomic data set in what follows for the present work.

Table 1. Calculated and Experimental Lattice Parameters of Sr-In Elements

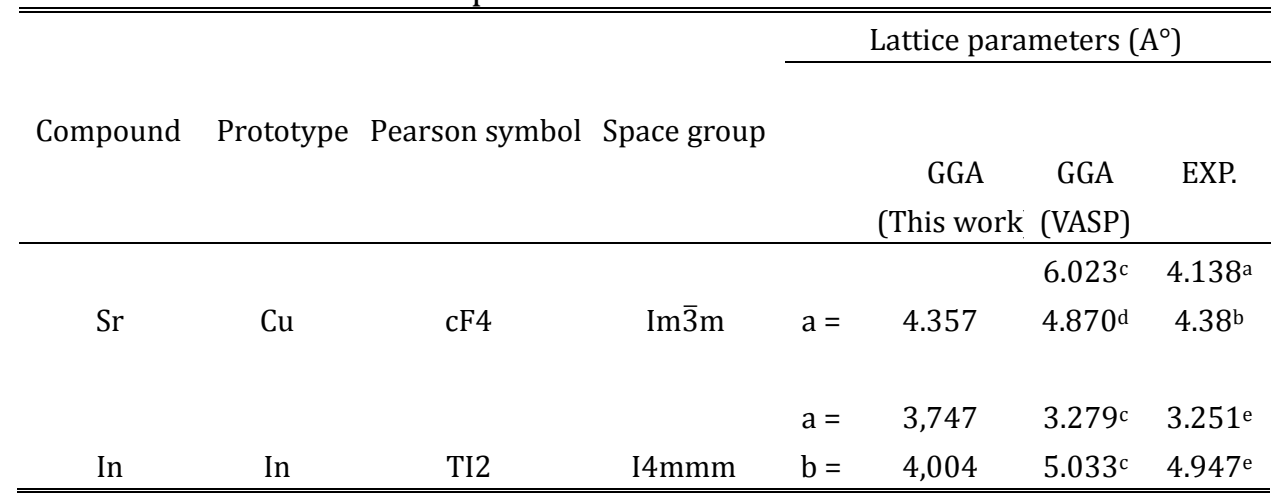

a Ref [17], b Ref [5], c Ref [1],, Ref [18], e Ref [6].

\subsection{Intermetallic Compounds}

We calculated the equations of state of the six known SrIn structures: the three hexagonal structureshp6 (P6/mmm), hp8(P6 $3 / \mathrm{mmc})$ and hp6 $\left(\mathrm{P}_{3} / \mathrm{mmc}\right)$ and the tow cubic oF64(Fdd2) and cF16(Fm3m) and finally the tow tetragonal structures tI $32(14 \mathrm{mcm})$ and TI2(I4 $\mathrm{mmm})$. The EOS were obtained by calculating twenty first principles data points for a given structure in a range of $\pm 10 \%$ of the equilibrium volume and sometimes more points were added in compression. For each point both of external and internal degrees of freedom of the structure are fully relaxed at constant volume. The obtained set of points was then fitted to a Birch-Murnaghan 4th-order EOS. The fitting of these energy-volume data is made using the EOS utility implemented in the ELK code [19]. Fig. 2 shows State equations (Energy vs volume) of the compounds $\mathrm{Sr}_{3} \mathrm{In}$ and $\operatorname{Sr}_{5} \operatorname{In}_{3}, \operatorname{SrIn}_{2}, \operatorname{SrIn}_{3}$ and $\operatorname{SrIn}_{5}$.
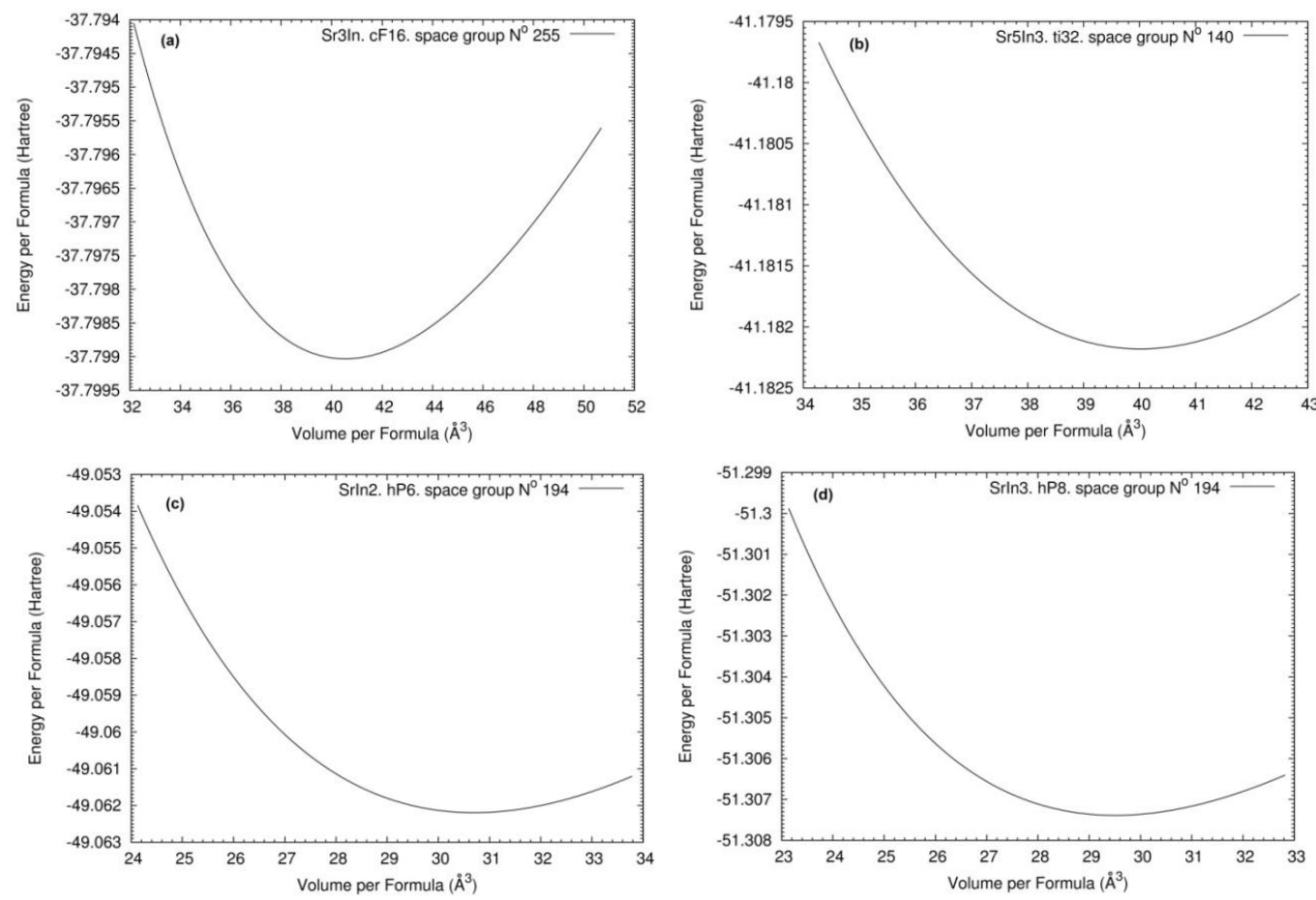


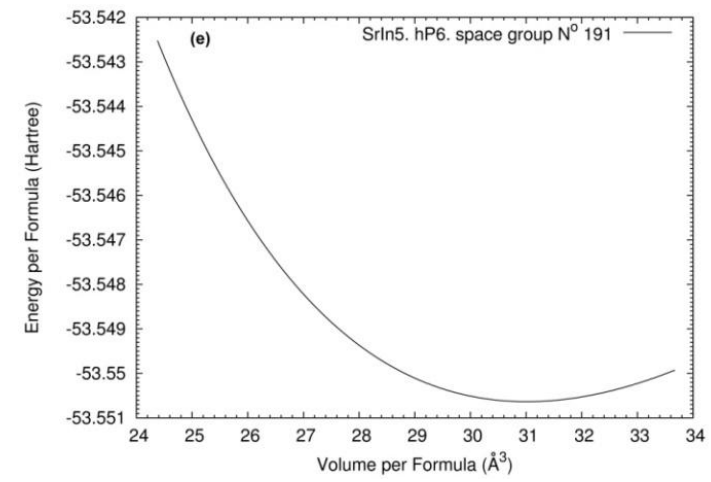

Fig. 2. Calculated total energies as a function of volume (a) Sr3In, (b) Sr5In3, (c) SrIn2, (d) SrIn3, (e) SrIn5.

The currently accepted Sr-In phase diagram contains eight intermetallics. But the crystallographic structures of two compounds are not known $\left(\mathrm{Sr}_{2} \mathrm{In}_{5}\right.$ and $\left.\mathrm{Sr}_{2} \mathrm{In}_{3}\right)$, so we have study the six compounds which there structure are determined. Their structural information and optimized lattice constants are summarized in Table 2 along with theoretical results [1] and experimental data [2], [7], [8], [20]. As expected, Our results which are in agreement with experiments show the usual trends of GGA in underestimating the bonding and resulting in smaller cohesive energies and larger lattice parameters which are closer to experimental data with a mean of error between $0.3 \%$ and $8.9 \%$, all calculations of errors were performed by making the comparison with the last column of experimental data of Table 2. Calculated enthalpies of formation are presented in Table 3 and Fig. 3 with experimental and other calculated values from literature for comparison. One can note that the current results may be taken as a starting point for further experimental or computational investigations.

Table 2. Calculated and Experimental Lattice Parameters of Sr-In Intermetallics

\begin{tabular}{|c|c|c|c|c|c|c|c|}
\hline \multirow[t]{2}{*}{ Compound } & \multirow[t]{2}{*}{ Prototype } & \multirow[t]{2}{*}{ Pearson symbol } & \multicolumn{5}{|c|}{ Lattice parameters $\left(\mathrm{A}^{\circ}\right)$} \\
\hline & & & Space group & & $\begin{array}{c}\text { GGA } \\
\text { (This work) }\end{array}$ & $\begin{array}{c}\text { GGA } \\
\text { (VASP) }\end{array}$ & EXP. \\
\hline \multirow{3}{*}{$\operatorname{SrIn}_{5}$} & & & & $\mathrm{a}=$ & $6.392(7.6 \%)$ & $6.301^{\mathrm{a}}$ & $5.937 \mathrm{~b}$ \\
\hline & $\mathrm{CaCu}_{5}$ & hp6 & $\mathrm{P} 6 / \mathrm{mmm}$ & $c=$ & $5.259(8.9 \%)$ & $5.270^{\mathrm{a}}$ & $4.827^{b}$ \\
\hline & & & & $\mathrm{a}=$ & $7.182(6.1 \%)$ & $7.141^{\mathrm{a}}$ & $6.769 \mathrm{~b}$ \\
\hline \multirow[t]{2}{*}{$\operatorname{SrIn}_{3}$} & $\mathrm{Mg}_{3} \mathrm{Cd}$ & hP8 & $\mathrm{P}_{3} / \mathrm{mmc}$ & $c=$ & $5.272(3.8 \%)$ & $5.249 \mathrm{a}$ & $5.481^{b}$ \\
\hline & & & & $\mathrm{a}=$ & 5.099 & $5.080^{\mathrm{a}}$ & \\
\hline \multirow[t]{2}{*}{$\operatorname{SrIn}_{2}$} & $\mathrm{CaIn}_{2}$ & hP6 & $\mathrm{P}_{3} / \mathrm{mmc}$ & $c=$ & 8.170 & $8.116^{a}$ & $8.021^{\mathrm{c}}$ \\
\hline & & & & $\mathrm{a}=$ & $10,10(1.2 \%)$ & $10.222^{\text {a }}$ & $10.230^{d}$ \\
\hline \multirow[t]{3}{*}{ SrIn } & SrIn & oF64 & Fdd2 & $\mathrm{b}=$ & $25,77(1.4 \%)$ & 26.040 a & $26.140^{d}$ \\
\hline & & & & $c=$ & $8,827(5.1 \%)$ & $8.365^{\mathrm{a}}$ & $8.400^{d}$ \\
\hline & & & & $\mathrm{a}=$ & $8,811(0.8 \%)$ & $8.788^{a}$ & $8.744^{\mathrm{e}}$ \\
\hline $\mathrm{Sr}_{5} \mathrm{In}_{3}$ & $\mathrm{Cr}_{5} \mathrm{~B}_{3}$ & $\mathrm{tI} 32$ & $\mathrm{I} 4 \mathrm{mcm}$ & $c=$ & $16,48(0.3 \%)$ & $16.496^{a}$ & $16.429 \mathrm{e}$ \\
\hline $\mathrm{Sr}_{3} \mathrm{In}$ & $\mathrm{BiF}_{3}$ & $\mathrm{cF} 16$ & $\mathrm{Fm} \overline{3} \mathrm{~m}$ & $\mathrm{a}=$ & $9.032(8.0 \%)$ & $8.639 a$ & $8.360 \mathrm{f}$ \\
\hline
\end{tabular}

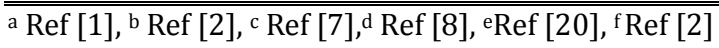


Table 3. Calculated and Experimental Enthalpies of Formation of Sr-Ge Intermetallics (kJ/mol)

\begin{tabular}{cccc}
\hline Compound & $\begin{array}{c}\text { GGA } \\
\text { (This work) } \\
\text { Abinit }\end{array}$ & $\begin{array}{c}\text { GGA } \\
\text { (VASP) } \\
{[1]}\end{array}$ & $\begin{array}{c}\text { CALPHAD } \\
{[1]}\end{array}$ \\
\hline $\mathrm{Sr}_{3} I n$ & -11.30 & -13.54 & -22.00 \\
$\mathrm{Sr}_{5} \mathrm{In}_{3}$ & -35.14 & -33.86 & -34.00 \\
$\mathrm{SrIn}$ & -43.76 & -42.62 & -42.84 \\
$\mathrm{SrIn}_{2}$ & -46.74 & -45.45 & -45.00 \\
$\mathrm{SrIn}_{3}$ & -33.69 & -32.58 & -37.70 \\
$\mathrm{SrIn}_{5}$ & -15.57 & -14.97 & -26.00 \\
\hline \hline
\end{tabular}

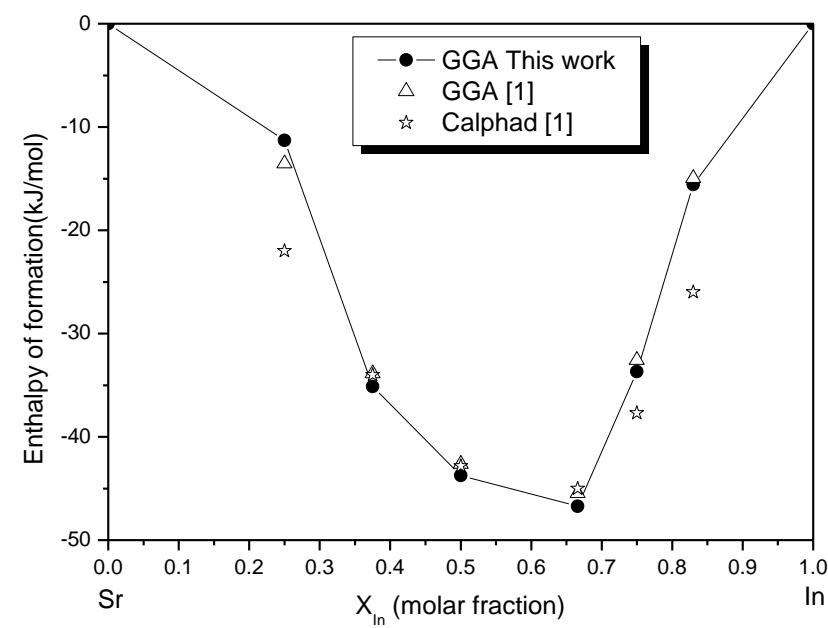

Fig. 3. Calculated enthalpies of formation for the Sr-In system compared with the first-principles calculations and the experimental data.

We havealso calculated the equilibrium volume and the Bulk-modulus with its first and second pressure derivatives of the six compounds by fitting the calculated energies versus volume to the fourth-order Birch-Murnaghan equation of state. The results are shown in Table 4. We have not found any values for these parameters in the literatures to compare with our results.

Table 4. Calculated Atomic Volume $\left(\mathrm{V}_{0}, \mathrm{~A}^{3} /\right.$ atom $)$, Bulk Modulus $\left(\mathrm{B}_{0}, \mathrm{GPa}\right)$, with Its First and Second

\begin{tabular}{llllll}
\multicolumn{5}{c}{ Pressure Derivatives (B'), (B", GPa ${ }^{-1}$ ) for SrIn Compounds } \\
\hline \hline & Sr3In.cF16 & Sr5In3.ti32 & SrIn2.hp6 & SrIn3.hp8 & SrIn5.hp6 \\
\hline $\mathrm{V}_{0}$ & 46.050 & 39.998 & 30.665 & 29.436 & 30.015 \\
B $_{0}$ & 17.687 & 21.214 & 32.469 & 27.777 & 31.295 \\
B'$_{0}$ & 3.94 & 3.21 & 4.36 & 5.04 & 4.51 \\
B" $^{\prime \prime} .10^{-3}$ & -0.044 & 0.061 & -0.0046 & 0.056 & -0.103 \\
\hline
\end{tabular}

\section{Conclusion}

Through first-principles local density functional calculations, we have investigated the ground state line of the system Sr-In. We have calculated the enthalpies of formation of six compounds reported in the phase diagram $\left(\operatorname{SrIn}_{5}, \mathrm{SrIn}_{3}, \mathrm{SrIn}_{2}, \operatorname{SrIn}, \mathrm{Sr}_{5} \mathrm{In}_{3}\right.$ and $\left.\mathrm{Sr}_{3} \mathrm{In}\right)$. The established ground state shows that, the two compounds $\operatorname{SrIn}_{5}$ and $\mathrm{Sr}_{3} \mathrm{In}$ are not in the ground state line and therefore note stable at $0 \mathrm{~K}$. it is recommended to perform another study by introducing the effect of temperature on the stability of the two compounds mentioned above.

\section{Acknowledgment}


The financial support of the Algerian General Direction for Scientific Research and Technological Development (PNR No. 8/u05/4532) is gratefully acknowledged.

The Inorganic Material Database (http://crystdb.nims.go.jp/crystdb) was used to obtain some crystallographic data of some structures.

\section{References}

[1] Wang, Y., Xin, J., Chen, C., Liu, S., Hu, B., \& Du, Y. (2014). Thermodynamic assessment of the Sr-In and Sr-Bi systems supported by first-principles calculations. Calphad, 45, 49-54.

[2] Bruzzone, G. (1966). The binary systems Sr-In and Ba-In. Journal of the Less Common Metals, 11, 249-258.

[3] Bruzzone, G., Franceschi, E., \& Merlo, F. (1978). M5X3 intermediate phases formed by Ca, Sr and Ba. Journal of the Less Common Metals, 60, 59-63.

[4] White, C. E. T., \& Okamoto, H. (1992). Phase Diagrams of Indium Alloys and Their Engineering Applications. Utica, N.Y. : Materials Park, Ohio: Indium corporation of America; American society for metals.

[5] Hirst, R., King, A., \& Kanda, F. (1956). Ba-Sr equilibrium diagram. J. Phys. Chem, 60, 302-304.

[6] Moshopoulou, E. G., Ibberson, R. M., Sarrao, J. L., Thompson, J. D., \& Fisk, Z. (2006). Structure of Ce2RhIn8: An example of complementary use of high-resolution neutron powder diffraction and reciprocal-space mapping to study complex materials. Acta Crystallographica Section B, 62, 173-189.

[7] Iandelli, A. (1964). MX2-Verbindungen der Erdalkali-und Seltenen Erdmetalle mit Gallium, Indium und Thallium (MX2-compoundsofalkaline earth metals and Rare earth metals withgallium, indium andthallium). Journal of Inorganic and General Chemistry, 330, 221-332.

[8] Wendorff, M., \& Röhr, C. (2005). Binäre Indide AInx ( $\mathrm{x}=1$, 2, 4; A = Ca, Sr, Ba, K, Rb) - Untersuchungen zu Strukturchemie und chemischer Bindung (binary indides $\operatorname{AIn}_{x} B$ Binäre Indide $\operatorname{AInx}(x=1,2,4 ; A=C a$, $\mathrm{Sr}, \mathrm{Ba}, \mathrm{K}, \mathrm{Rb})$ - studies on Structural Chemistry and Chemical Bonding). Journal of Inorganic and General Chemistry, 631, 338-349.

[9] Gonze, X., Rignanese, G.-M., \& Caracas R. (2005). First-principle studies of the lattice dynamics of crystals, and related properties. Z. Kristallogr, 220, 458-472.

[10] Gonze, X., Beuken, J.-M., Caracas, R., Detraux, F., \& Fuchs, M., et al. (2002). First-principles computation of material properties: The ABINIT software project. Comput. Mater. Sci, 25, 478-492.

[11] Kohn, W., \& Sham, L. J. (1965). Self-consistent equations including exchange and correlation effects. Phys. Rev, 140, A1133.

[12] Blöchl, P. E. (1994). Projector augmented-wave method. Phys. Rev. B, 50, 17953-17979.

[13] Torrent, M., Jollet, F., Bottin, F., Zérah, G., \& Gonze, X. (2008). Implementation of the projector augmented-wave method in the ABINIT code: Application to the study of iron under pressure. Comput. Mater. Sci, 42, 337-351.

[14] Perdew, J. P., Burke, K., \& Ernzerhof, M. (1996). Generalized gradient approximation made simple. Phys. Rev. Lett, 77, 3865.

[15] Tackett, A., Holzwarth, N., \& Matthews, G. (2001). A projector augmented wave (PAW) code for electronic structure calculations, part II: Pwpaw for periodic solids in a plane wave basis. Comput. Phys. Commun, 135, 348-376.

[16] Marzari, N. (1996). Ab-Initio Molecular Dynamics for Mrtallic Systems. Cambridge University.

[17] Palenzona, A., \& Pani, M. (2005). The phase diagram of the Sr-Ge system. Journal of Alloys and Compounds, 402, 136-140.

[18] Du, Y., Li, L., Wang, J., Wang, J., \& Jin, Z. (2009). A thermodynamic description of the Ge-Sr system 
acquired via a hybrid approach of CALPHAD and first-principles calculations. Calphad, 33, 719-722.

[19] The Elk FP-LAPW Code. From http://elk.sourceforge.net/

[20] Wendorff, M., \& Röhr, C. (2004). Neue erdalkalimetall-reiche binäre Indide: Ca2In, Sr28In11 und Sr5In3 (New alkaline earth rich binary indides: $\mathrm{Ca}_{2} \mathrm{In}_{,} \mathrm{Sr}_{28} \mathrm{In}_{11}$ and $\mathrm{Sr}_{5} \mathrm{In}_{3}$ ). Journal of Nature Research $B, 59 b$, 619-628.

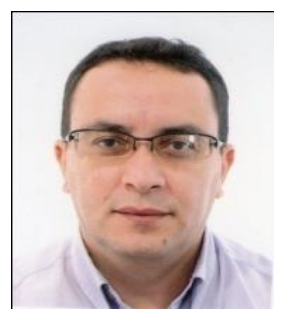

Raouf Beddiaf was born at Batna governorate, Algeria in 1974. He received his $\mathrm{PhD}$ degree in 2015 from Batna University. He is an assistant professor at the Department of Technology, Batna University Algeria, from 2003 until now. His research interests are focused on the investigation of materials properties obtained from first principles calculations using ABINIT code.

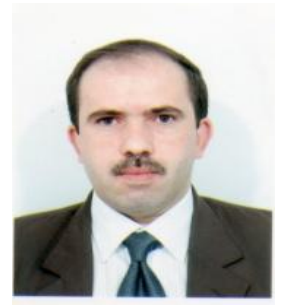

Yassine Djaballah received his PhD degree in materials science from Batna University, Algeria in 2005. He received the habilitation research from Batna University in 2010. He was an assistant professor at the Department of Physics, Batna University Algeria, from 2003 to 2010. He is currently a professor at the Physics Department, Batna University Algeria. His research interests are in materials science, thermodynamic modeling of multi component systems and ab-initio calculation of metallic alloys.

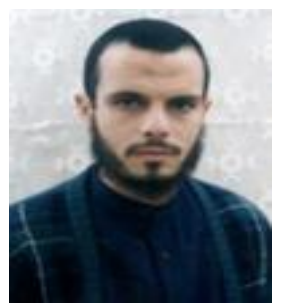

Hichem Bouderba received his $\mathrm{PhD}$ degree in solid state physics from Batna University, Algeria in 2012. He is an assistant professor at the Department of technical sciences at the University of Ghardaia, Algeria, from 2012. His research interests are focused on the investigation of materials properties obtained from first principles calculations. 